\title{
Salutogenesis for Thriving Societies
}

\author{
Maurice B. Mittelmark, Monica Eriksson, Shifra Sagy, \\ Jürgen M. Pelikan, Lenneke Vaandrager, \\ Claudia Meier Magistretti, Bengt Lindström, \\ and Georg F. Bauer
}

\section{Introduction}

In Chap. 3 of this handbook, Mittelmark and Bauer characterise salutogenesis as having several meanings. Salutogenesis may refer to the overall salutogenic model described in Antonovsky's 1979 Health, Stress, and Coping. In narrower meaning, salutogenesis is often equated with one part of the model, the sense of coherence (SOC). These first two meanings relate to the theory of salutogenesis. In its most general meaning, salutogenesis refers to a salutogenic orientation, focusing attention on the origins of health, assets for health

M. B. Mittelmark ( $₫)$

Department of Health Promotion and Development, Faculty of

Psychology, University of Bergen, Bergen, Norway

e-mail: maurice.mittelmark@uib.no

\section{Eriksson}

Department of Health Sciences, Section of Health Promotion and Care Sciences, Center on Salutogenesis, University West, Trollhättan, Sweden

\section{S. Sagy}

Martin Springer Center for Conflict Studies, Ben-Gurion

University of the Negev, Be'er Sheva, Israel

J. M. Pelikan

WHO-Collaborating Centre for Health Promotion in Hospitals and Healthcare at the Austrian National Public Health Institute (Gesundheit Österreich GmbH), Vienna, Austria

L. Vaandrager

Department of Social Sciences, Health and Society, Wageningen

University and Research, Wageningen, The Netherlands

C. Meier Magistretti

Centre for Health Promotion and Participation, Lucerne University of Applied Sciences and Arts, Lucerne, Switzerland

B. Lindström

NTNU Center for Health Promotion Research, Norwegian University of Science and Technology, Trondheim, Norway e-mail: bengtblind@hotmail.com

\section{G. F. Bauer}

Center of Salutogenesis, Division of Public and Organizational Health, Epidemiology, Biostatistics and Prevention Institute,

University of Zürich, Zürich, Switzerland

e-mail: georg.bauer@uzh.ch and well-being (contra a pathogenic orientation, which is paradoxically quite prominent in health promotion practice and research).

We envision a three-pronged approach to advance salutogenesis in all three meanings:

- Theory development of the overall salutogenic model and continued emphasis on the study of the SOC.

- Sound application of the theory of salutogenesis in health services, health promotion and other areas (e.g. community development) leading to a 'salutogenesis of sustainable, inclusive thriving'.

- Capacity building for advancement as an academic field (infrastructure, organisations, education).

This approach is aligned closely with suggestions for future directions that we, with other colleagues in the Global Working Group on Salutogenesis, have published elsewhere (Bauer et al., 2020). Here, we further address the ambition to advance salutogenesis, inspired by the stimulating experience of working together to undertake this second edition of the handbook.

\section{Theory Development}

Emerging theoretical interests taken up in this volume include:

- Salutogenesis at various levels of social organisation (i.e. cities and towns, schools, universities, workplaces, healthcare settings, whole communities, nations).

- Salutogenesis as a framework to understand and promote health at different stages of peoples' lives.

- Salutogenesis in perspectives other than stress and coping theory (e.g. well-being, thriving, attribution theory).

- Salutogenesis applied to societal arenas beyond the healthcare sector (i.e. conflict studies, peace education, architecture, social policy making). 
The question arises, to what degree is our work on these themes contributing to advancing the formal salutogenic model of health and the concept of SOC? As Kuhn (1970) famously theorised, scientific revolution follows periods of 'normal science' by pushing paradigms and their theories beyond their limits. That requires communities of scholars to hold to their common viewpoints - to hold focus - pressing to beyond the breaking point. Indeed, Antonovsky (1996) dared to suggest the salutogenic model as potentially triggering a paradigm shift in the health sciences. This is a grand idea, and it is inspirational to us, the editors of this book.

To advance salutogenesis as a theory, we need to be explicit about our core theoretical interest: rigorously developing and testing the salutogenic model of health and salutogenic interventions to create, promote and restore well-being.

A stimulating example of how this might be approached is the emerging synergy model of health (Pérez-Wilson et al., 2020). This model integrates key concepts of the salutogenic theory (sense of coherence, generalised and specific resistance resources and deficits), with the assets model of health, within the framework of Bronfenbrenner's ecological health model. The synergy model of health illuminates the feasibility of applying salutogenic theory to achieve action for wellbeing and strengthens the theoretical fundament of the assets model.

Besides the concept of salutogenesis, other positive concepts of health have emerged over the years (see, for example, the chapter on positive psychology in this volume). Systematic reviews of such related concepts are a priority. For example, an umbrella metaphor is widely used to illuminate salutogenesis' close kinship with other health resources/ assets models (Lindström \& Eriksson, 2010). Under the umbrella are a host of related concepts from a wide range of health models and theories, which share a fundamental feature: the concepts focus on resources for well-being (contra risk factors for illness). These concepts need to be theoretically examined to help distinguish similarities and differences. This would open a large field of transdisciplinary research, wherein researchers from diverse disciplines - not just health promotion - would feel at 'home' working with salutogenesis theory and theory-based practice. An example of the research we are calling for here is Haugan and Eriksson's (2021) analysis of concepts such as the SOC, dignity, hope, flourishing, belonging, self-efficacy, and will to meaning and willpower. What are needed are in-depth analyses of how these and related concepts are interrelated from the theoretical standpoint of salutogenesis.

Our coming theoretical explorations should also take us a step back from questions about the relationship of the SOC to health and to probe questions about the genesis of salutogenic processes generally and the SOC in particular. There are indications that experience in infancy, and perhaps even before birth, influences SOC development (Lindstrom, 2017). It seems quite sure - and in line with Antonovsky's theorising - that early childhood is a vital formative period for acquiring resistance resources and SOC development. In line with our interest in a salutogenesis of thriving, public health scholars are advancing the notion of nurturing childcare (Read, 2014). Nurturing care has the goal of moving the child health goalposts from 'surviving to thriving', especially in parts of the world that have until recently been locked onto the prevention of child morbidity and mortality (Urke et al., 2018).

Finally, our collaborative work on theory should address an urgent theoretical issue: adding a positive health continuum and a path of positive health development to the original salutogenic model (Bauer et al., 2020). This expansion is needed to evolve the salutogenic model to a theory for health promotion, also capturing positive human health experience.

\section{Applying the Salutogenic Model}

As to headway in applying salutogenesis to address society's practical needs, this volume is a testament to significant progress, showing the possibilities in a wide range of settings - towns, schools, universities, prisons, workplaces, care institutions, whole communities, the military and educational institutions. This illustrates the tremendous diversity of opportunity of a salutogenic orientation to improve virtually all of society's well-being, as expressed, for example, in the United Nation's Sustainable Development Goals. Among innovations in applied salutogenesis are new interventions to strengthen 'Sense for Coherence' (Koelen \& Lindström, 2016; Lindström \& Eriksson, 2010; Magistretti et al., 2019):

...it is important for the professional to have a sense of how to improve the sense of coherence of the people we work for, in other words the professional should develop a sense FOR coherence. (Koelen \& Lindström, 2016, p. 34)

\section{Capacity Building}

Here, we consider salutogenesis in the context of building capacity (infrastructure, organisations, education) needed to support its continued development. The feasibility of teaching the practice of salutogenesis in colleges and universities has been amply demonstrated (Langeland et al., 2016). The chapter in this handbook by Vaandrager and colleagues, Salutogenesis Post-Graduate Education: Experience from the European Perspective on Health Promotion Summer Courses, 1991 to the Present, demonstrated the feasibility of grounding post-graduate and continuing education on the salutogenic model. 
Why not teach salutogenesis at all levels and across the breadth of education? Why not in the arts and sciences beyond the health arena? Why not in the training of teachers and social services workers? Why not in public safety and rescue/emergency services workers - or even in general manager/leadership training in business schools?

If 'spreading the word' about salutogenesis is a worthy endeavour, should not the lead be in the hands of the Society for Theory and Research on Salutogenesis? It will be daunting to stretch beyond the health arena's familiar territory; is our sense of coherence fit to take on this task? Much of what is reported in this volume suggests we are ready. As a publication of the Society, this handbook is hands-on evidence that we are serious in our purpose. This is a call for the Society - for us! - to develop and deploy a full and imaginative array of activities, services and capacity-building enterprises to help advance salutogenesis.

In our efforts to advance salutogenesis, we should seek to learn from others; to take on innovative ideas suggested in other fields. Here are some examples from the far afield community of computational biologists (Ross-Hellauer et al., 2020). Like salutogenesis, it is a field in its infancy, or at least in its formative years, with inspiring ideas that we might learn from:

- Plan for dissemination: define objectives and map potential new audiences. This might be done even more effectively in the future through STARS: Society for Theory And Research on Salutogenesis (https://www.starssociety.org/), which was established precisely to bridge between the Global Working Group on Salutogenesis and the broader scientific community working in areas other than health promotion.

- Keep the right profile: use social media, personal websites, organisational websites and academic networks to highlight salutogenesis. When persons seeking to learn about salutogenesis seek information on the Internet, let us be sure that they are informed not just of publications but also people, places and institutions they can contact to get involved.

- Encourage participation: actively invite and engage others to participate and collaborate.

- Select Open Access: the first edition of this handbook was ranked third in Springer's open access listing in 2020, in terms of the number of downloads. Salutogenesis will enjoy dramatically greater attention if future publishing prioritises open access options over more traditional communication formats.

- Go live: TEDx talks, science festivals and road shows are becoming important dissemination channels for science, and salutogenesis has a long way to go in $t$ aking advantage of these newer communication opportunities.
- Go for deep networking: currently, the global working group puts together an EU funded proposal (COST action) for developing a broad, international network of salutogenesis researchers working towards the vision of "salutogenesis of just, inclusive thriving'.

- Evaluate: we need to be systematic in disseminating salutogenesis and evaluating how we are doing. Do we have the impact we wish for, what works well, what works less well?

\section{The COVID-19 Crisis: Relevance for the Vision of Salutogenesis for Thriving Societies}

We are writing this final chapter in the handbook's second edition amid a severe pandemic. COVID-19 has shaken up lives worldwide and has changed perceptions about life for many. Naturally, the present pandemic encourages research on pathogenic questions relating to the disease's aetiology, its prevention and its cure. Is a salutogenic approach to COVID-19 research also relevant? What can be the fruits of employing this approach? Members of the society are now addressing these questions with publications soon available (Mana \& Sagy, 2020; also https://www.stars-society.org/). A unique role for salutogenesis in tackling COVID-19 - and any future pandemic - is being articulated at present by Maass and colleagues in a publication underway:

\begin{abstract}
Salutogenesis can make valuable contributions in tackling pandemics by providing a positive focus, identifying individual and collective resources, and by highlighting the importance of coherent measures and communication strategies. (the citation to the published paper will be posted at https://www.starssociety.org/)
\end{abstract}

This summarises well a niche in the health and social sciences that salutogenesis is uniquely suited to fill. Pandemics are inevitably part of the human experience in the river of life, along with the many other trying experiences that are inextricable aspects of daily living. While many others in science properly tackle the tribulations of living with attention mainly to deficits and risks, salutogenesis' attention is tuned to nurturing the resources, opportunities and strengths that support the strong sense of coherence that nourishes thriving individuals and societies.

\section{Salutogenesis for Thriving Societies}

How might we summarise our aspirations? Let us introduce a new vision: Salutogenesis for thriving societies. Reaching beyond salutogenesis' original focus on the origins of individuals' ease/dis-ease in the 'river of life', salutogenesis for thriving calls for supporting individuals', families', neighbourhoods' and communities' strengths and opportunities, in 
support of health in its broadest sense. Therefore, the range of our ambition must be enormous, from supporting coping with individual illness and social dysfunction to contributing to a global cultural value supporting thriving (not just surviving) in just, inclusive societies.

The ambitious roadmap that we need for this journey is thankfully already at hand! The salutogenesis community's contributions to achieving the UN Sustainable Development Goals would support planetary thriving (indeed 'health for all').

Are we poised at the start of a transition to a 'salutogenesis of thriving'? The answer lies in our hands as we shape the coming development of salutogenesis theory, research and practice. The expansion of the salutogenic model by a path of positive health and well-being development is essential to advance a salutogenesis of societal thriving. We are sure Aaron Antonovsky would have welcomed this expansion. In Unraveling the Mystery of Health (1987), he wrote:

If the SOC is indeed related to health, should it not then reasonably be expected to be related to a variety of aspects of wellbeing? If successful coping with life stressors has positive consequences for health, should it not also have positive consequences for satisfaction, happiness, morale, and positive affect? (ibid, p. 180)

Might he just as well have added 'thriving' to his positive consequences list, had the thought occurred to him? We think so.

\section{References}

Antonovsky, A. (1996). The salutogenic model as a theory to guide health promotion. Health Promotion International, 11(1), 11-18.

Bauer, G. F., Roy, M., Bakibinga, P., Contu, P., Downe, S., Eriksson, M., Espnes, G. A., Jensen, B. B., Canal, D. J., Lindström, B., Mana, A., et al. (2020). Future directions for the concept of salutogenesis: A position article. Health Promotion International, 35(2), 187-195.

Haugan, G., \& Eriksson, M. (Eds.). (2021). Health promotion in health care - vital theories and research. Springer Nature, 2021.
Koelen, M., \& Lindström, B. (2016). Health promotion philosophy and theory. In C. A. Dardet, A. B. Tomas, G. Boonekamp, E. Breton, P. Contu, E. Fosse, A. Hofmeister, D. Juvinya, L. Kennedy, M. A. Koelen, B. Lindstrom, G. Masanotti, G. Pavlekovic, G. Pocetta, L. Vaandrager, \& A. Wagemakers (Eds.), Twenty-five years of capacity building: The ETC healthy learning process (pp. 21-37). Retrieved from https://etcsummerschool.files.wordpress. com/2016/08/etc-book-2016.pdf

Kuhn, T. (1970). The structure of scientific revolutions (2nd ed.). University of Chicago Press.

Langeland, E., Gjengedal, E., \& Vinje, H. F. (2016). Building salutogenic capacity: A year of experience from a salutogenic talk-therapy group. International Journal of Mental Health Promotion, 18(5), 247-262.

Lindstrom, B. (2017). Genesis on the origin of a lifelong salutogenic process. BepSalut. 15. Recovered: http://www.udg.edu/bepsalut.

Lindström, B., \& Eriksson, M. (2010). The hitchhiker's guide to salutogenesis: Salutogenic pathways to health promotion. Folkhälsan.

Magistretti, C., Topalidou, A., \& Meinecke, F. (2019). The sense FOR coherence: An empirical approach to a new concept. In C. Meier Magistretti, B. Lindström, \& M. Eriksson (Eds.), Know and understand salutogenesis: Concept, significance, research and practical applications. Hogrefe. (in German).

Mana, A., \& Sagy, S. (2020). Brief report: Can political orientation explain mental health in the time of a global pandemic? Voting patterns, personal and national coping resources, and mental health during the coronavirus crisis. Journal of Social and Clinical Psychology, 39(3), 187-193. https://doi.org/10.1521/jscp.2020.39.3.165

Pérez-Wilson, P., Marcos-Marcos, J., Morgan, A., Eriksson, M., Lindström, B., \& Álvarez-Dardet, C. (2020). "A synergy model of health": An integration of salutogenesis and the health assets model. Health Promotion International, 1-11. https://doi.org/10.1093/ heapro/daaa084.

Read, V. (2014). Developing attachment in early years settings: Nurturing secure relationships from birth to five years. Routledge.

Ross-Hellauer, T., Tennant, J. P., Banelytė, V., Gorogh, E., Luzi, D., Kraker, P., Pisacane, L., Ruggieri, R., Sifacaki, E., \& Vignoli, M. (2020). Ten simple rules for innovative dissemination of research. PLoS Computational Biology, 16(4), e1007704. https://doi. org/10.1371/journal.pcbi.1007704

Urke, H. B., Mittelmark, M. B., Amugsi, D. A., \& Matanda, D. J. (2018). Resources for nurturing childcare practices in urban and rural settings: Findings from the Colombia 2010 Demographic and Health Survey. Child: Care, Health and Development, 44(4), 572-582.

Open Access This chapter is licensed under the terms of the Creative Commons Attribution 4.0 International License (http://creativecommons. org/licenses/by/4.0/), which permits use, sharing, adaptation, distribution and reproduction in any medium or format, as long as you give appropriate credit to the original author(s) and the source, provide a link to the Creative Commons license and indicate if changes were made.

The images or other third party material in this chapter are included in the chapter's Creative Commons license, unless indicated otherwise in a credit line to the material. If material is not included in the chapter's Creative Commons license and your intended use is not permitted by statutory regulation or exceeds the permitted use, you will need to obtain permission directly from the copyright holder. 